\title{
The Interdisciplinary Education for Chinese Universities Under the Innovation-driven Strategy
}

\author{
Shuguang Liu ${ }^{1}$, Jianli Wang ${ }^{1}$ and Yungui Shi ${ }^{1}$ \\ ${ }^{1}$ School of Mechanical and electrical Eng., Huangshan University, Huangshan 245041
}

Keywords: Innovation driven; University; Interdisciplinary education; Innovation ecosystem

\begin{abstract}
The social \& economic development of a country/region has experienced three stages: factors of production driven, capital driven, innovation driven. During the innovation driven stage, the sustainable development of society rely on individuals with great innovative capability and aggregation of different organizations. In the past 30 years, the inner knowledge production and outer knowledge flow of universities has changed profoundly. The tradition of openness and competitiveness of university further promote its knowledge flow with other innovation bodies. The knowledge spillover and knowledge diffusion will continue to deepen in multiple areas like entrepreneurship spirit fostering, university innovation technology transfer and university - industry collaboration mechanism. So, the interdisciplinary approach will be applied to develop students' interdisciplinary knowledge structure, thinking abilities, which becomes the necessary way for Chinese universities to first-class undergraduate teaching. These changes not only facilitate the knowledge production of university, but form the regional innovation ecosystem.
\end{abstract}

\section{Innovation Driven by the Transformation of Function of Colleges and Universities}

The Connotation of Innovation Drive. Innovation drive this concept is the earliest put forward by Harvard University professor Michael porter, he divided economic development into four stages: the first stage is the cheap productivity, natural resources and other factors of production driven stage; The second stage is the massive investment, improve the technology and equipment to support economic development period of investment; The third stage is give priority to in order to improve innovation ability; The fourth stage is the wealth effect in the combination of innovation and market stage.[1]

Innovation drive this concept in terms of its nature, refers to a country/region of social progress and economic growth is mainly rely on the original knowledge to explore \# the creation of new inventions and new technology and its application process. From the experience of developed countries, a driven by innovation of social economy requires the following necessary conditions: first, in the field of various industries and has the innovation spirit and innovation ability of individuals, such as \# scientists, teachers, researchers, entrepreneurs, engineers and technicians, etc. The cultivation of the innovator is the basis and prerequisite of the innovation driven process operation, therefore, aims to encourage and facilitate innovators system of the external environment and a series of measures, is especially important. Second, the original knowledge and all kinds of invention from theory to practice the application of full transformation process. Compared with the investment drive and driven factors of economic development, the embodied innovation drive is some kind of similar to spontaneous evolution characteristics of ecosystem, the dynamics, habitat and growing, to create the ultimate value as the guidance, all innovation finally to have the possibility of implementation under certain social conditions. Third, the innovation drive embodies is a kind of from bottom to top, different between regional diversity, spontaneous evolution and open interaction. As a result, a region, a country, a society's openness and diversity is the key to prosperity and innovation, tolerance means that allow the existence of the difference, and open means break the closed boundary, interactive inspired ideas and concepts of infinite possibility.

Innovation Driven by the Transformation of Function of Colleges and Universities. The function of the university knowledge innovation is the knowledge production, diffusion and spread, its role is the discovery of new knowledge, new theory by applying research to basic research results into products with market value, through cooperative research and development of new 
products, new technology, new industries. Innovation process has many features: first, it is a process of free inquiry, so you can't have a strong planning; It has the risk of failure, the outlook is uncertain, and will not produce immediate economic effect, need the government's subsidies, the market economy is failure; Requires interdisciplinary range of long-term research and a loose, encourages exploration and failure of the external environment; It is more important to a group of innovative academics and students. Romer will output the representative figure of new growth theory is divided into two departments, namely consumer goods production department and $\mathrm{r} \& \mathrm{~d}$ department. Knowledge spillover effect and the spillover of knowledge not only to form self incremental effect, and make the material capital and labor and other inputs with incremental effect, leading to long-term growth without restraint. American university for about three 5 of the basic research, more than one hundred research university is the key basic scientific research. Stanford university, university of California, Berkeley, university of California, San Diego, such as semiconductor, computer, electromechanical integration science research center. Innovation is not a linear or mechanical process, but is seen as many aspects in our economy and society is multifaceted and constantly interacting ecosystem. The university and the private sector in the innovation of ecological research partnerships, "the report further to:" in this ecosystem, including from academia, industry, foundation, science, and a series of economic organizations and governments at all levels of the actors. The widely acknowledged its non-linear and interaction at the same time, the most concise, innovation process can be regarded as a new knowledge and technology process of the two, this is a research to find the basis of the process of marketization.".[2]

Continental European countries, such as France and Germany in the field of basic research with universities maintain close relations of cooperation. In France, for example, founded in 1939, the French national center for scientific research (CNRS) is the basis of the research department, under the leadership of the largest research institutions, scientific research funds for scientific research in colleges and universities for several times. Scientific research work of the university of France, except under the guidance of a scientific research department of the ministry of education to accept the management of the technical department, so keep close relationship of the CNRS, CNRS subordinates is associated with university, two-thirds of the laboratory center around $70 \%$ of the staff is the joint laboratory work. CNRS through sign long-term package of research collaboration agreement with the university, on the financial resources to provide long-term funding for university. The United States is directly to the big federal laboratory set up in universities, especially research universities.

Innovation driven not simply as a kind of economic and social development path, its ultimate goal is to realize the modernization of the state, society, individual. As the deep change of the era of transition countries, the modernization of the meaning of modern China and developed countries must be different, its modernization should be combined with its own historical and cultural traditions, economic and social structure, political system and the system characteristics, driving force of innovation and the country's economic and social development strategy together.

\section{The Connotation and Features of the IDE}

Interdisciplinary (Interdisciplinary, also translated as "Interdisciplinary") originally appeared in the mid $1920 \mathrm{~s}$, in western literature refers to the beyond a single discipline boundary and involve two or more disciplines of knowledge creation and communication activities.[3] Promote interdisciplinary research committee of the national academy of sciences, said: "the interdisciplinary refers to through the integration of the two and more academic or professional knowledge system of information, data, technology, according to the theory, perspective, concepts, and to the promotion of basic to understand or solve the problem of a single subject or field is difficult to solve."[4] can be seen, interdisciplinary nature is to break the disciplinary boundaries, it includes both natural science and humanities + cross each subject in the field of social science, also includes the intersection of three kinds of subjects.

Interdisciplinary activities increasingly extensive inevitably lead to traditional branch of university to the university of interdisciplinary profound transformation. Interdisciplinary university 
as a new model, not only in professional, course setting is interdisciplinary characteristics, and the education idea, education goals, teaching methods, teaching structure is different from traditional branch of university.

University IDE is to use interdisciplinary approach, aims to cultivate students to form the interdisciplinary knowledge structure, a new interdisciplinary thinking ability and cultivate interdisciplinary education paradigm, it is to the deep deconstruction of traditional academic/professional education and reform, and compared with the traditional academic/professional education are essentially different.

University of IDE has the following distinctive features: first, the education purpose of completely-new innovation significance. University IDE broke through the traditional academic/professional education will personal to imprison in a particular field, its fundamental purpose is through the multidisciplinary education and research, cultivate a strong theoretical foundation, grasp the multi-discipline knowledge, proficient in a variety of skills, good at using innovative scientific thinking, with compound knowledge, ability and quality structure of innovative talents, brought about the naissance of the emerging disciplines at the same time, promote the progress of science and technology, realize the innovative talent training and scientific research development of "win-win". Secondly, its teaching content is complex and cross. University IDE continue the tradition to explore the profound knowledge, and from the characteristics and needs of modern scientific activities highlighted by focusing on a particular problem or theory related to multiple disciplines, in the field of view, such as paradigm for content and consolidation, emphasized in the form of a new change of traditional single academic/professional teaching contents, principles and methods of the internal, pay attention to promoting the fusion of knowledge system and to construct, so that the original dispersed in a single academic/professional fuzzy concept clearer, systematic, and by establishing the connection between different areas, making each other open and closed between knowledge integration. Third, its teaching mode has significant research. The university IDE combines interdisciplinary teaching, research, finally to realize the innovation of the personnel training and scientific research. It introduces study of undergraduate course teaching, emphasizing the teacher USES research-based teaching, student to carry on the investigative study, interactive teaching research. So that their mode of inquiry, the participatory teaching is not only to completely change the traditional academic/professional education of non-computer majors, cramming method of teaching, and the original education is always in a state of confrontation in the mode of teaching and learning, teaching and research, both to reinvent the contradiction, realize the integration of the two unification.

\section{The Implementation of the Interdisciplinary Education Path}

Establish the System of Leadership Organization, the Construction Plan and Related Supporting System. First of all, to establish and improve the specialized agencies, such as IDE committee for the implementation of the IDE to provide leadership. Specifically, in the school, the faculty level, to set up the IDE leading group and IDE steering committee, establish and perfect the system of normal work and mechanism, and according to the need to regularly or irregularly research and solve the problems existing in the IDE, the policy, system, personnel, and budget devoted to tilt, practical and will boost the IDE as a big thing to grasp. At the same time, through coordination and promote IDE committee, promote the school different departments. Different professional dialogue and cooperation in personnel training and collaborative innovation.

Second, has its own characteristics, to develop and implement the first-class university undergraduate teaching construction plan based on the IDE. The key lies in strengthening characteristics of the development of the concept, improving the quality of talents training target, explore the path of the IDE. We have to learn to draw lessons from the development of high-level university experience both at home and abroad, has its own characteristics, to set the first-class university undergraduate teaching construction plan based on the IDE, clear in implementing school development goals and should be as in interdisciplinary talents training target.

Optimizing Curriculum System, Reforming Teaching Mode. First of all, to adjust the project 
of cultivating undergraduates, in cultivating talents for the target certain professional training scheme, on the basis of orientation to foster interdisciplinary project of cultivating innovative talents as the goal of the transition, make its direct impact on learners by knowledge level to ability quality level of progressive and radiation. Second, curriculum and teaching reform is based on the IDE first-class undergraduate teaching construction, the core of cultivating interdisciplinary innovative talents and the foothold, must break the barrier of the discipline of education between, according to the principle of "professional, thick foundation" wide, adjusting and optimizing curriculum system, integrating professional courses, vigorously develop and strive for the construction of a high level of interdisciplinary comprehensive course, scatter undergraduate course is connected into a linked course system, pay attention to the comprehensive quality of undergraduates cultivation and invasion of the multidisciplinary field of vision. Third, the interdisciplinary curriculum development process, is also different disciplines teachers around a theme to communicate, collision, collaborative process. To encourage teachers to explore new territory in the discipline specialized fundamental course, focusing on high quality courses, pays special attention to the integration of curriculum knowledge and optimization, active interdisciplinary curriculum, content and method of exploration IDE.[5]

Make International Communication Platform. Should make full use of university internationalization development opportunity, and strive to the internationalization through first-class construction in all aspects of undergraduate course teaching based on the IDE. To further build and improve the international communication platform system, exploring the interdisciplinary collaborative education mechanism of international cooperation. Exchanging and give full play to the "111 innovation base", to develop new cooperation platform, and further intensify the introduction of foreign intelligence, promote overseas talents with the campus backbone of academic research, to cultivate innovative talents. At the same time, on the basis of institute of silk road construction, highlight the characteristics of school education internationalization. Around the national strategic goals, vigorously implement the area along the "shortage of talent training course construction, establish service" area "geological resources for the construction of outstanding features, the exchanges and cooperation base of balanced development of various disciplines, and attract more excellent students and students in the region to participate in school international subject research and cooperation

\section{References}

[1] Michael E. Porter: The Competitive Advantage of Nations (The world culture publishing company, America 1996), p.87.

[2] Information on http://en.wikipedia.org/wiki/University of Wisconsin\% E2\% 80\% 93Madison

[3] Z.L. Liu: Crossover study of interdisciplinary sciences era (Studies in Science of Science, China 1993), p.9.

[4] Committee on Facilitating Interdisciplinary Research, Notional Academy of Sciences, National Academy of Engineering \& Institute of Medicine. Facilitating Interdisciplinary Research[R]. Washington, D.C: The National Academies Press, (2004) No.2, p185.

[5] W. Zhang and X.D. Zou: Studies in Dialectics of Nature | Stud Dialect Nat, Vol 15 (2012) No.3, p.61. 